\title{
Colifagos como indicadores de contaminación fecal y de remoción bacteriana en la potabilización del agua
}

\section{Coliphages as fecal pollution and removal bacterial indicators in the drinking water process}

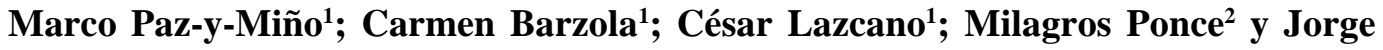 \\ León ${ }^{2}$
}

Presentado: $14 / 11 / 2003$

Aceptado: $\quad 25 / 11 / 2003$

\section{Resumen}

El presente trabajo analiza la eficacia del tratamiento de agua procedentes del río Rímac. Se comparan muestras de agua no tratadas con las fases sucesivas del tratamiento: decantación, filtración y clorinación. La cuantificación de colifagos fue realizada por los métodos de Capa Simple y Filtro de Membrana. Los Coliformes Totales (CT), Coliformes Termotolerantes (CTT) y Bacterias Heterótrofas $(\mathrm{BH})$ fueron determinados por los métodos del Número Más Probable (NMP) y Filtro de Membrana. La cepa estándar de E. coli C ATCC 13706 fue utilizada como hospedera de colifagos. Los promedios de colifagos cuantificados fueron de $2267,25 \mathrm{UFP} / 100 \mathrm{~mL}$ en las muestras sin tratamiento; 2,$11 ; 2,04$ y 1,07 UFP/100 mL en las muestras procedentes de la decantación, filtración y clorinación respectivamente. No se detectaron CT y CTT en muestras de agua clorinada. La correlación entre colifagos y CT en muestras de agua decantada y filtrada ( $r=0,3793$ y $r=0,3629$ respectivamente) fueron significativas $(p<0,05)$. En las muestras de agua sin tratamiento no fueron significativas las correlaciones $(r=0,3048, p>0,05)$. La correlación entre colifagos y los CTT con las muestras de tratamientos fue significativa $(r=0,7129 ; 0,5326$ y 0,4612, para muestras con decantación, filtración y clorinación respectivamente, $\mathrm{p}<0,05)$. Los porcentajes de remoción microbiana respecto de la muestras de agua sin tratamiento fueron del $99,95 \%$ para los colifagos, 99,99\% para las $\mathrm{BH}$ y $>99,99 \%$ para los CT y CTT.

Palabras clave: Colifagos, coliformes, contaminación, remoción microbiana, tratamiento del agua, Rio Rímac, Lima, Perú.

\section{Abstract}

This work compare the efficiency of water treatment from Rimac river. Samples from different phases of water treatment (decanted, filtered and chlorinated) were compared with not treated samples. Coliphages quantification was made by Simple Layer and Membrane Filter methods. Most Probable Number (NMP) and Membrane Filter methods were used to assessment of Total Coliforms, Coliforms Thermotolerants and Heterotrophic Bacteria. The standard strain of E. coli C ATCC 13706 was used as coliphages host.

The averages of quantified coliphages were of $2267,25 \mathrm{UFP} / 100 \mathrm{~mL}$ in samples with out treatment; $2,11,2,04$ and $1,07 \mathrm{UFP} / 100 \mathrm{~mL}$ in the water samples from decanted, filtered and chlorinated treatment respectively. Total Coliforms and Coliforms Thermotolerants were not detected in samples of chlorinated water. The correlation between coliphages and Total Coliforms in samples of decanted and filtered water $(r=0,3793$ and $r=0,3629$ respectively) were significant $(p<0,05)$ Samples with out treatment don't were significant $(r=0,3048, p>0,05)$. Correlations between coliphages and the Coliforms Thermotolerants were significant with water samples from treatment decanted, filtered and chlorinated $(r=0,7129 ; 0,5326$ and $0,4612, p<0,05)$. The microbial removal percentages were $99,95 \%$ for the coliphages, $99,99 \%$ for the $\mathrm{BH}$ and $>99,99 \%$ for the CT and CTT. Peru.

Keywords: Coliphages, Coliforms, pollution, microbial removal, water treatment, Rimac river, Lima,

\footnotetext{
${ }^{1}$ Laboratorio de Biología y Desinfección, Planta de Tratamiento del Agua - La Atarjea, Lima - Perú.

${ }^{2}$ Microbiología Ambiental y Biotecnología, Facultad de Ciencias Biológicas - UNMSM.

Jorge León E-mail: jleonq@unmsm.edu.pe
} 


\section{Introducción}

Las materias fecales del hombre y de los animales contienen una gran variedad de microorganismos enteropatógenos como Campylobacter, Salmonella, Shigella, Yersinia, Aeromonas, Pasteurella, Francisella, Leptospira, Vibrio, protozoarios y varios grupos de virus. Cuando estos microorganismos son descargados en aguas naturales, su presencia denota contaminación fecal y constituyen un riesgo de trasmisión de enfermedades para la población humana (Borrego et al., 1990).

Los bacterias enteropatógenos por lo general aparecen en cantidades bajas en aguas naturales, razón por lo cual su detección en el laboratorio se logra con cierta dificultad. Por otro lado, las técnicas de cultivo para su aislamiento son complejas y laboriosas. Estas desventajas han llevado a diseñar técnicas microbiológicas para el análisis de agua basadas en la detección de otros microorganismos presentes en las materias fecales y que puedan servir de indicadores (Borrego et al., 1990).

Aunque los Coliformes Totales, Coliformes Fecales, Enterococos y Escherichia coli son utilizados como indicadores de contaminación fecal, su uso ha presentado algunas desventajas, ya que han sido reportados casos de enfermedades entéricas por consumo de agua en la cual no se había detectado coliformes. Además, ninguno de estos microorganismos sirven como indicadores de contaminación viral (Borrego et al., 1987). Por esto los virus de Escherichia coli conocidos como colifagos pueden ser mejores indicadores de contaminación fecal. La presencia de colifagos en heces humanas y desagües es constante y su detección es fácil y rápida (Wentsel et al., 1982; Cornax et al., 1991). Los colifagos son virus que infectan células de $E$. coli y han sido aisladas fácilmente de aguas contaminadas conjuntamente con los coliformes totales y termotolerantes (Grabow et al. 1984). Además de ser indicadores de contaminación fecal son también considerados como indicadores de la presencia de enterovirus en aguas naturales y tratadas (IAWPRC, 1991).

Estudios sobre aguas han sugerido el uso de los colifagos como indicadores de la eficacia del proceso de remoción microbiana en plantas de tratamiento durante la potabilización del agua (Jofre et al., 1995). Esto se debe a la capacidad de estos virus de ser más resistentes al proceso de tratamiento del agua que las bacterias indicadoras convencionales (Payment \& Franco, 1993).

La Planta de Tratamiento de La Atarjea SEDAPAL, tiene al río Rímac como única fuente de abastecimiento para la obtención de agua potable para la ciudad de Lima; sin embargo, estas aguas se encuentran con alta carga microbiana, y por ello deben ser tratadas rigurosamente con el fin de disminuir la contaminación microbiológica a niveles aceptables (Barzola et al., 1995a). Para evaluar la eficacia en el tratamiento y desinfección del agua en esta planta se realiza la cuantificación de Coliformes Totales (CT) y Coliformes Termotolerantes (CTT) como indicadores de contaminación fecal y de las Bacterias Heterótrofas $(\mathrm{BH})$ como indicadoras de la eficacia del proceso de remoción de la carga microbiana (Barzola et al., 1995b). Sin embargo, estos microorganismos pueden ser evaluados por la presencia de los colifagos en las diferentes muestras durante las etapas de potabilización del agua. El presente trabajo evalúa la presencia de los colifagos y su correlación con los coliformes y bacterias heterótrofas en las fases sucesivas del tratamiento de agua: decantación, filtración y clorinación. Para ello, se aplica una metodología simple y rápida en la cuantificación de coliformes y colifagos tanto en muestras de agua sometidas a tratamiento como en aguas no tratadas.

\section{Material y Metodos}

\section{Toma de Muestras}

Las muestras de agua fueron consideradas en dos grupos: muestras no tratadas, re- 
colectadas en el lugar de captación del agua del río Rímac («Bocatoma») (agua con alta carga orgánica y microbiana) y muestras en tratamiento, denominadas como (a): agua decantada (agua clarificada por filtración a través de mantos de lodo), (b): agua filtrada (agua luego de atravesar la capa de arena de $1 \mathrm{~m}$ de espesor) y (c): agua clorinada (agua luego de haber recibido dosificación de cloro final de $1,8 \mathrm{mg} / \mathrm{L}$ ). Todas las muestras correspondieron a las pozas ubicadas en las instalaciones de la Planta de Tratamiento del Agua $N^{\circ} 1$ de La Atarjea. Las muestras fueron colectadas con una frecuencia de tres veces por semana hasta hacer un total de 40 por cada uno de los cuatro puntos de muestreo. Las muestras se tomaron en frascos de vidrio de boca ancha estériles de 500 y $1000 \mathrm{~mL}$ de capacidad, a los cuales previamente se agregaron $0,1 \mathrm{~mL} / 100 \mathrm{~mL}$ de muestra de una solución de tiosulfato de sodio al 1,8\% (p/v) como declorinante. Las muestras fueron mantenidas a temperatura de refrigeración $\left(8^{\circ} \mathrm{C}\right)$ por un máximo de 2 horas desde su colecta hasta su procesamiento en los laboratorios de análisis de SEDAPAL. Adicionalmente se hicieron las mediciones de $\mathrm{pH}$, turbiedad y cloro residual según los métodos estándares del APHA (1989).

\section{Cuantificación de Coliformes Totales, Coliformes Termotolerantes y Bacterias Heterótrofas}

La cuantificación de los coliformes totales (CT) y coliformes termotolerantes (CTT) en muestras de agua de «Bocatoma» se realizó por el método del Número Más Probable (NMP) (APHA, 1989), usando los siguientes medios de cultivo y condiciones de incubación:

- CT: Caldo Lauril Triptosa (Merck) más Púrpura de Bromocresol al 0,001 \% (p/v) incubado a $35{ }^{\circ} \mathrm{C}$ por $24-48$ h y confirmado con Caldo Lactosado Verde Brillante Bilis (CLVBB, Merck) incubado a $35^{\circ} \mathrm{C}$ por $24-48 \mathrm{~h}$.

- CTT: Caldo A-1 (Difco) incubado a 35 ${ }^{\circ} \mathrm{C}$ por $3 \mathrm{~h}$ y luego a $44,5{ }^{\circ} \mathrm{C}$ por $21 \mathrm{~h}$. Los resultados se reportaron como Número Más Probable (NMP)/100 mL.
La cuantificación de los CT y CTT en muestras de agua en tratamiento (decantada, filtrada y clorinada) se realizó por el método de Filtro de Membrana (APHA, 1989) usando los siguientes medios de cultivo y condiciones de incubación:

- CT: Agar Endo-Less (Difco) incubado a $35^{\circ} \mathrm{C}$ por $24 \mathrm{~h}$.

- CTT: Agar M-Fc (Difco) incubado a 35 ${ }^{\circ} \mathrm{C}$ por $3 \mathrm{~h}$ y luego a $44,5{ }^{\circ} \mathrm{C}$ por $21 \mathrm{~h}$.

En ambos casos se utilizaron membranas de filtración estériles cuadriculadas, blancas, de $47 \mathrm{~mm}$ de diámetro y $0,45 \mathrm{~mm}$ de diámetro de poro (Gelman Sciences). Los resultados se reportaron como Unidades Formadoras de Colonia (UFC)/100 mL.

La cuantificación de las bacterias heterótrofas $(\mathrm{BH})$ en muestras de agua de «Bocatoma» y agua en tratamiento se realizó por el método de Filtro de Membrana (APHA, 1989) utilizando el Agar R2A (Difco) y filtros de membrana de color negro (Gelman Sciences), incubando a $35{ }^{\circ} \mathrm{C}$ por $48 \mathrm{~h}$. Los resultados se reportaron como Unidades Formadoras de Colonia (UFC)/mL.

\section{Preparación de la Cepa Hospedera E. coli C ATCC 13706}

La preparación de la cepa hospedera $E$. coli C ATCC 13706 para la cuantificación de colifagos se realizó según APHA (1989). La cepa hospedera mantenida en cultivo stock en Agar Tripticasa Soya (TSA, Merck) más glicerina al $10 \%$ (v/v), se reactivó en $10 \mathrm{~mL}$ de Caldo Tripticasa Soya (TSB, Merck) e incubado a $35{ }^{\circ} \mathrm{C}$ por $18-24 \mathrm{~h}$. Transcurrido el tiempo se homogenizó el cultivo y se agregó a un frasco de vidrio conteniendo $25 \mathrm{~mL}$ de TSB más glicerina al $10 \%$. Se incubó a $35^{\circ} \mathrm{C}$ por $18 \mathrm{~h}$ hasta obtener una densidad óptica (DO) de 0,5 a $520 \mathrm{~nm}$ (equivalente a $1 \times 10^{9}$ células/ $\mathrm{mL}$ ). La lectura de la densidad óptica se realizó en un espectrofotómetro (Spectronic) previamente calibrado con TSB más glicerina estéril. El cultivo se repartió en volúmenes de 2,5 mL en crioviales (Corning) estériles y sometidas luego 
Tabla 1. Recuento de coliformes, colifagos y bacterias heterótrofas en muestras de agua no tratada («Bocatoma») en la Planta de Tratamiento № 1 - La Atarjea.

AGUA NO TRATADA ("Bocatoma»)

\begin{tabular}{|c|c|c|c|c|}
\hline Muestra & $\begin{array}{l}\mathbf{a} \text { CT } \\
(\log \mathrm{NMP} / 100 \mathrm{~mL})\end{array}$ & $\begin{array}{c}\text { CTT } \\
(\log \mathrm{NMP} / 100 \mathrm{~mL})\end{array}$ & $\begin{array}{c}\text { Cf } \\
(\log \mathrm{UFP} / 100 \mathrm{~mL})\end{array}$ & $\begin{array}{c}\mathbf{B H} \\
(\log \mathrm{UFC} / \mathrm{mL})\end{array}$ \\
\hline 1 & 5,23 & 4,04 & 3,50 & $7,00 \times 10^{4}$ \\
\hline 2 & 4,68 & 3,85 & 3,26 & $7,60 \times 10^{4}$ \\
\hline 3 & 5,04 & 3,60 & 3,00 & $8,00 \times 10^{5}$ \\
\hline 4 & 5,04 & 4,43 & 3,54 & $9,10 \times 10^{4}$ \\
\hline 5 & 4,48 & 4,48 & 3,54 & $7,00 \times 10^{4}$ \\
\hline 6 & 5,11 & 3,90 & 3,40 & $4,20 \times 10^{4}$ \\
\hline 7 & 5,70 & 4,43 & 3,54 & $2,10 \times 105$ \\
\hline 8 & 5,48 & 4,28 & 3,38 & $1,50 \times 10^{5}$ \\
\hline 9 & 4,40 & 4,11 & 3,29 & $5,00 \times 10^{5}$ \\
\hline 10 & 4,70 & 4,28 & 3,52 & $2,40 \times 10^{4}$ \\
\hline 11 & 4,70 & 4,04 & 3,03 & $2,00 \times 10^{5}$ \\
\hline 12 & 4,11 & 4,04 & 3,05 & $1,80 \times 10^{4}$ \\
\hline 13 & 4,40 & 4,38 & 3,39 & $7,90 \times 10^{3}$ \\
\hline 14 & 4,70 & 4,40 & 3,55 & $4,50 \times 10^{4}$ \\
\hline 15 & 5,20 & 4,04 & 3,12 & $5,00 \times 10^{5}$ \\
\hline 16 & 5,23 & 4,11 & 3,29 & $2,60 \times 10^{5}$ \\
\hline 17 & 4,48 & 4,43 & 3,49 & $4,60 \times 10^{6}$ \\
\hline 18 & 5,04 & 4,38 & 3,45 & $2,50 \times 10^{4}$ \\
\hline 19 & 4,48 & 4,38 & 3,58 & $1,10 \times 10^{5}$ \\
\hline 20 & 5,11 & 4,38 & 3,58 & $3,40 \times 10^{1}$ \\
\hline 21 & 4,40 & 4,11 & 3,36 & $3,10 \times 10^{4}$ \\
\hline 22 & 4,70 & 4,48 & 3,47 & $1,00 \times 10^{4}$ \\
\hline 23 & 4,70 & 4,11 & 3,43 & $3,30 \times 10^{4}$ \\
\hline 24 & 4,40 & 4,38 & 3,57 & $1,40 \times 10^{4}$ \\
\hline 25 & 4,48 & 3,85 & 3,20 & $6,00 \times 10^{3}$ \\
\hline 26 & 5,04 & 4,00 & 3,29 & $9,20 \times 10^{4}$ \\
\hline 27 & 5,04 & 3,90 & 3,28 & $4,50 \times 10^{6}$ \\
\hline 28 & 4,70 & 3,30 & 3,21 & $1,60 \times 10^{6}$ \\
\hline 29 & 4,40 & 4,04 & 3,30 & $1,00 \times 10^{4}$ \\
\hline 30 & 5,04 & 4,43 & 3,48 & $6,30 \times 10^{4}$ \\
\hline 31 & 4,11 & 3,85 & 3,09 & $1,90 \times 10^{4}$ \\
\hline 32 & 4,40 & 4,04 & 3,14 & $1,80 \times 10^{4}$ \\
\hline 33 & 4,40 & 3,85 & 3,22 & $9,80 \times 10^{4}$ \\
\hline 34 & 4,11 & 3,85 & 3,13 & $7,20 \times 10^{4}$ \\
\hline 35 & 4,65 & 4,11 & 3,41 & $1,80 \times 10^{4}$ \\
\hline 36 & 5,04 & 4,40 & 3,56 & $6,50 \times 10^{4}$ \\
\hline 37 & 4,70 & 4,40 & 3,52 & $6,80 \times 10^{4}$ \\
\hline 38 & 4,70 & 4,43 & 3,40 & $4,20 \times 10^{4}$ \\
\hline 39 & 4,38 & 4,38 & 3,46 & $2,60 \times 10^{4}$ \\
\hline 40 & 4,78 & 4,04 & 3,22 & $5,60 \times 10^{4}$ \\
\hline
\end{tabular}

CT: Coliformes Totales; CTT: Coliformes Termotolerantes; Cf: Colifagos; BH: Bacterias Heterótrofas 
a refrigeración por 1 hora y posterior conservación a una temperatura de $-20{ }^{\circ} \mathrm{C}$ por un tiempo no mayor de 6 semanas.

\section{Cuantificación de Colifagos por el méto- do de Capa Simple}

El método de Capa Simple, recomendado por APHA (1989), fué utilizado para la cuantificación de colifagos en las muestras de agua de «Bocatoma». Para ello, la cepa hospedera mantenida en crioviales se descongelaron calentando en baño maría a $45^{\circ} \mathrm{C}$. Por otro lado, se colocaron dos tubos de prueba con 5,5 mL de TSA modificado (TSA + 0,16 y $0,21 \%$ de nitrato de amonio y nitrato de estroncio respectivamente), licuado y mantenidos a $45-50{ }^{\circ} \mathrm{C}$. Se añadió a cada tubo $1 \mathrm{~mL}$ del cultivo de la cepa hospedera, $0,08 \mathrm{~mL}$ del colorante Cloruro de Trifenil Tetrazolio (TTC, Sigma) al $1 \%$ (p/v) y $5 \mathrm{~mL}$ de muestra de agua de «Bocatoma». Se agitaron los tubos en un vórtex y se vertieron en placas de petri estériles de 15x100 mm. Se dejaron solidificar a temperatura ambiente y se incubaron a $35^{\circ} \mathrm{C}$ por $4 \mathrm{~h}$. Se contaron las placas de lisis formadas, reportándose los resultados como Unidades Formadoras de Placas (UFP)/100 mL.

\section{Cuantificación de Colifagos por el méto- do de Filtro de Membrana}

El método de Filtro de Membrana (según Alonso et al., 1994) se aplicó para determinar colifagos presentes sólo en las muestras de agua en tratamiento (decantada, filtrada y clorinada). Para ello, se descongelaron crioviales conteniendo la cepa hospedera y manteniéndose en baño maría a $45{ }^{\circ} \mathrm{C}$. Se colocaron dos tubos de prueba con $5 \mathrm{~mL}$ de TSA modificado más Polisorbato de Sodio (Tween 80, Difco) al 0,3\% (v/v) licuado y mantenido en baño maría a $45-50{ }^{\circ} \mathrm{C}$. Se añadió a cada tubo $1 \mathrm{~mL}$ de la cepa hospedera y $0,08 \mathrm{~mL}$ del colorante TTC al 1\%. Se agitaron los tubos en un vórtex y se vertieron en placas de petri estériles de 15x60 mm dejando solidificar a temperatura ambiente. Las muestras de agua a analizarse fueron previamente tratadas con Cloruro de Magnesio a una con- centración final de $0,05 \mathrm{M}\left(\mathrm{Cl}_{2} \mathrm{Mg} \cdot 6 \mathrm{H}_{2} \mathrm{O}\right.$, Sigma; 4,75 g de cloruro de magnesio por 1000 $\mathrm{mL}$ de muestra). Se filtraron $500 \mathrm{~mL}$ de agua decantada, $500 \mathrm{~mL}$ de agua filtrada y 1000 $\mathrm{mL}$ de agua clorinada. El procedimiento de filtración fue similar a la realizada para el análisis de CT y CTT, con la diferencia que en el presente caso las membranas luego del filtrado fueron colocadas en posición invertida, es decir en contacto con la superficie del medio previamente inoculado con la cepa hospedera. La incubación fue a $35^{\circ} \mathrm{C}$ por $6-8 \mathrm{~h}$. Las placas de lisis se contaron como zonas claras sobre un fondo rojo, color debido al desarrollo bacteriano en presencia de TTC. Los resultados para su interpretación se reportaron como UFP/100 mL. En todos los casos los ensayos se hicieron por duplicado y con controles.

\section{Determinación del porcentaje de remo- ción microbiana.}

El porcentaje de remoción microbiana en las muestras tratadas (agua decantada, filtrada y clorinada) se obtuvo a partir de los valores obtenidos en la cuantificación de CT, CTT y BH en las muestras de «Bocatoma». Para hallar la carga microbiana removida en cada etapa de tratamiento en estudio se aplicó una regla de tres simple considerando el valor de la media geométrica hallada para las muestras de «Bocatoma» (100\% de recuento) como el valor referencial. Se determinó el porcentaje de la carga microbiana presente en cada muestra y por consiguiente el valor diferencial representó el porcentaje de bacterias removidas en cada etapa del tratamiento del agua.

\section{Resultados}

\section{Cuantificación de Coliformes Totales, Coliformes Termotolerantes y Bacterias Heterótrofas}

El análisis de bacterias del grupo coliforme y bacterias heterótrofas en las muestras de agua no tratadas («Bocatoma») arrojaron resultados en términos generales cuantitativamente elevadas; siendo las medias geométricas alcanzadas para los CT del orden de 5,63 x 104 NMP/100 $\mathrm{mL}$, mientras que para los CTT éstas alcan- 
Tabla 2. Recuento de coliformes, colifagos y bacterias heterótrofas en muestras de agua tratadas en la Planta de Tratamiento № 1 - La Atarjea.

\begin{tabular}{|c|c|c|c|c|c|c|c|c|c|c|c|c|}
\hline \multirow[b]{2}{*}{ No } & \multicolumn{4}{|c|}{ AGUA DECANTADA } & \multicolumn{4}{|c|}{ AGUA FILTRADA } & \multicolumn{4}{|c|}{ AGUA CLORADA } \\
\hline & CT & CTT & $\mathbf{C f}$ & BH & CT & CTT & $\mathbf{C f}$ & BH & CT & CTT & Cf & BH \\
\hline 1 & 1,11 & 0,90 & 1,0 & $5,30 \times 10^{4}$ & 0,70 & 0,70 & 1,00 & $6,80 \times 10^{3}$ & 0 & 0 & 0 & 0 \\
\hline 2 & 0,00 & 0,00 & 0,90 & $3,60 \times 10^{4}$ & 0,00 & 0,00 & 0,90 & $1,70 \times 10^{3}$ & 0 & 0 & 0 & 2 \\
\hline 3 & 1,15 & 1,0 & 0,95 & $5,00 \times 10^{5}$ & 0,70 & 0,70 & 1,08 & $1,60 \times 10^{5}$ & 0 & 0 & 1 & 0 \\
\hline 4 & 0,78 & 0,48 & 0,90 & $7,00 \times 10^{3}$ & 0,60 & 0,30 & 0,95 & $1,20 \times 10^{3}$ & 0 & 0 & 0 & 0 \\
\hline 5 & 0,30 & 0,30 & 1,08 & $3,40 \times 10^{4}$ & 0,30 & 0,00 & 1,15 & $1,20 \times 10^{3}$ & 0 & 0 & 2 & 0 \\
\hline 6 & 0,60 & 0,00 & 1,11 & $3,00 \times 10^{4}$ & 0,60 & 0,60 & 1,11 & $5,30 \times 10^{3}$ & 0 & 0 & 2 & 0 \\
\hline 7 & 0,30 & 0,30 & 0,85 & $8,00 \times 10^{4}$ & 0,30 & 0,30 & 0,70 & $1,00 \times 10^{3}$ & 0 & 0 & 0 & 1 \\
\hline 8 & 0,48 & 0,30 & 0,78 & $2,60 \times 10^{4}$ & 0,60 & 0,60 & 0,70 & $2,40 \times 10^{4}$ & 0 & 0 & 0 & 0 \\
\hline 9 & 0,30 & 0,30 & 0,70 & $2,10 \times 10^{4}$ & 0,85 & 0,70 & 0,85 & $1,40 \times 10^{4}$ & 0 & 0 & 0 & 0 \\
\hline 10 & 0,30 & 0,30 & 0,60 & $2,30 \times 10^{4}$ & 0,00 & 0,00 & 0,70 & $5,00 \times 10^{3}$ & 0 & 0 & 0 & 1 \\
\hline 11 & 0,30 & 0,30 & 0,30 & $1,60 \times 10^{4}$ & 0,00 & 0,00 & 0,00 & $4,20 \times 10^{3}$ & 0 & 0 & 0 & 2 \\
\hline 12 & 0,30 & 0,30 & 0,30 & $7,10 \times 10^{3}$ & 0,30 & 0,30 & 0,30 & $7,90 \times 10^{3}$ & 0 & 0 & 0 & 1 \\
\hline 13 & 0,30 & 0,30 & 0,30 & $4,50 \times 10^{2}$ & 0,30 & 0,30 & 0,00 & $3,50 \times 10^{2}$ & 0 & 0 & 0 & 6 \\
\hline 14 & 0,00 & 0,30 & 0,30 & $1,50 \times 10^{4}$ & 0,70 & 0,48 & 0,00 & $3,00 \times 10^{2}$ & 0 & 0 & 0 & 1 \\
\hline 15 & 0,00 & 0,00 & 0,00 & $3,00 \times 10^{5}$ & 0,00 & 0,00 & 0,00 & $4,50 \times 10^{4}$ & 0 & 0 & 0 & 3 \\
\hline 16 & 0,30 & 0,30 & 0,48 & $7,10 \times 10^{4}$ & 0,30 & 0,30 & 0,00 & $1,00 \times 10^{4}$ & 0 & 0 & 0 & 1 \\
\hline 17 & 0,00 & 0,00 & 0,00 & $3,20 \times 10^{6}$ & 0,48 & 0,48 & 0,30 & $7,20 \times 10^{5}$ & 0 & 0 & 0 & 3 \\
\hline 18 & 0,00 & 0,00 & 0,48 & $3,10 \times 10^{5}$ & 0,00 & 0,00 & 0,00 & $2,20 \times 10^{5}$ & 0 & 0 & 0 & 1 \\
\hline 19 & 0,30 & 0,00 & 0,00 & $2,80 \times 10^{5}$ & 0,30 & 0,30 & 0,00 & $3,90 \times 1$ & $v$ & 0 & 0 & 2 \\
\hline 20 & 0,30 & 0,30 & 0,30 & $1,90 \times 10^{4}$ & 0,48 & 0,30 & 0,30 & $3,90 \times 10^{4}$ & 0 & 0 & 0 & 2 \\
\hline 21 & 0,30 & 0,30 & 0,70 & $8,30 \times 10^{4}$ & 0,48 & 0,30 & 0,48 & $6,20 \times 10^{4}$ & 0 & 0 & 0 & 1 \\
\hline 22 & 0,00 & 0,30 & 0,60 & $1,20 \times 10^{5}$ & 0,00 & 0,48 & 0,70 & $3,70 \times 10^{5}$ & 0 & 0 & 0 & 0 \\
\hline 23 & 0,48 & 0,30 & 0,30 & $1,40 \times 10^{4}$ & 0,90 & 0,48 & 0,60 & $9,60 \times 10^{4}$ & 0 & 0 & 0 & 1 \\
\hline 24 & 0,00 & 0,00 & 0,00 & $1,50 \times 10^{5}$ & 0,00 & 0,00 & 0,00 & $5,90 \times 10^{4}$ & 0 & 0 & 0 & 3 \\
\hline 25 & 0,00 & 0,00 & 0,00 & $6,50 \times 10^{3}$ & 0,00 & 0,00 & 0,30 & $2,90 \times 10^{4}$ & 0 & 0 & 0 & 1 \\
\hline 26 & 0,30 & 0,00 & 0,00 & $3,00 \times 10^{4}$ & 0,85 & 0,60 & 0,30 & $8,60 \times 10^{3}$ & 0 & 0 & 0 & 1 \\
\hline 27 & 0,00 & 0,00 & 0,00 & $4,80 \times 10^{5}$ & 0,00 & 0,00 & 0,00 & $1,40 \times 10^{5}$ & 0 & 0 & 0 & 10 \\
\hline 28 & 0,95 & 0,00 & 0,00 & $2,50 \times 10^{4}$ & 0,48 & 0,30 & 0,00 & $1,60 \times 10^{3}$ & 0 & 0 & 0 & 0 \\
\hline 29 & 0,60 & 0,00 & 0,00 & $1,30 \times 10^{4}$ & 0,00 & 0,00 & 0,00 & $1,60 \times 10^{4}$ & 0 & 0 & 0 & 3 \\
\hline 30 & 0,00 & 0,00 & 0,00 & $3,40 \times 10^{5}$ & 0,00 & 0,00 & 0,00 & $2,00 \times 10^{4}$ & 0 & 0 & 0 & 0 \\
\hline 31 & 0,30 & 0,30 & 0,00 & $5,60 \times 10^{4}$ & 0,30 & 0,30 & 0,00 & $5,40 \times 10^{4}$ & 0 & 0 & 0 & 1 \\
\hline 32 & 0,30 & 0,30 & 0,00 & $3,20 \times 10^{4}$ & 0,95 & 0,30 & 0,00 & $2,40 \times 10^{3}$ & 0 & 0 & 0 & 1 \\
\hline 33 & 0,30 & 0,30 & 0,00 & $3,00 \times 10^{4}$ & 0,30 & 0,30 & 0,00 & $2,40 \times 10^{4}$ & 0 & 0 & 0 & 1 \\
\hline 34 & 0,30 & 0,30 & 0,00 & $8,50 \times 10^{4}$ & 0,30 & 0,30 & 0,00 & $6,30 \times 10^{4}$ & 0 & 0 & 0 & 1 \\
\hline 35 & 0,00 & 0,00 & 0,00 & $1,20 \times 10^{4}$ & 0,00 & 0,00 & 0,00 & $3,20 \times 10^{3}$ & 0 & 0 & 0 & 1 \\
\hline 36 & 0,00 & 0,00 & 0,00 & $9,50 \times 10^{4}$ & 0,00 & 0,00 & 0,00 & $8,70 \times 10^{4}$ & 0 & 0 & 0 & 6 \\
\hline 37 & 0,30 & 0,30 & 0,00 & $7,40 \times 10^{4}$ & 0,30 & 0,30 & 0,00 & $9,30 \times 10^{4}$ & 0 & 0 & 0 & 4 \\
\hline 38 & 0,85 & 0,00 & 0,00 & $8,70 \times 10^{4}$ & 0,48 & 0,00 & 0,00 & $7,40 \times 10^{4}$ & 0 & 0 & 0 & 11 \\
\hline 39 & 0,00 & 0,00 & 0,00 & $4,80 \times 10^{4}$ & 0,00 & 0,00 & 0,00 & $2,00 \times 10^{4}$ & 0 & 0 & 0 & 1 \\
\hline 40 & 0,30 & 0,30 & 0,00 & $1,20 \times 10^{4}$ & 0,30 & 0,30 & 0,00 & $2,50 \times 10^{4}$ & 0 & 0 & 0 & 1 \\
\hline
\end{tabular}

CT: Coliformes Totales (Log UFC/100 mL); CTT: Coliformes Termotolerantes (Log UFC/100 mL); Cf: Colifagos (UFP/100 mL); BH: Bacterias Heterótrofas (log UFC/mL). 
zaron a $1,41 \times 10^{4} \mathrm{NMP} / 100 \mathrm{~mL}$; en tanto las $\mathrm{BH}$ presentaron una media geométrica de 7,55 x $10^{4} \mathrm{UFC} / \mathrm{mL}$ (Tabla 1 y 3 ).

Respecto a la cuantificación de CT y CTT en las muestras de agua decantada y agua filtrada, varias evaluaciones resultaron cuantitativamente negativas; por lo tanto, a estos resultados se sumó una unidad para determinar las medias geométricas. Los valores de las medias geométricas para CT y CTT en muestras de agua decantada fueron determinadas en el orden de 2,04 UFC/100 mL y 1,67 UFC/100 mL respectivamente; en tanto, la media geométrica para las $\mathrm{BH}$ fue de $4,8 \mathrm{x}$ $10^{4} \mathrm{UFC} / \mathrm{mL}$. Asimismo, el análisis cuantitativo de las muestras de agua filtrada arrojaron medias geométricas de 2,13 UFC/100 mL para los CT y de 1,81 UFC/100 mL para los CTT; mientras la media geométrica para las $\mathrm{BH}$ fue de 1,74 x $10^{4}$ UFC/ mL (Tabla 2 y 3 ).

Finalmente, al evaluar las muestras de agua clorinada para CT y CTT no se obtuvieron cuantificaciones positivas en ningún caso; sin embargo, para las $\mathrm{BH}$ se obtuvo una media geométrica de 2,23 UFC/ mL, valor compara- tivamente muy inferior a las otras muestras tal como se indican en las Tablas 2 y 3 .

\section{Cuantificación de Colifagos.}

La presencia de colifagos tanto en las muestras de agua no tratadas («Bocatoma») como en las muestras de agua decantada, filtrada y clorinada guarda cierta relación con los coliformes. Al cuantificar colifagos en las muestras de agua de «Bocatoma» se obtuvo una media geométrica de 2267,25 UFP/100 mL (Tabla 1 y 3). En cambio, para las muestras de agua decantada y agua filtrada se obtuvieron resultados negativos a varias cuantificaciones, siendo necesario sumar una unidad al resultado de cada evaluación para determinar las medias geométricas. De esta manera, de las muestras de agua decantada se obtuvo una media geométrica de 2,11 UFP/ $100 \mathrm{~mL}$; en tanto, de las muestras de agua filtrada la media geométrica obtenida fue de 2,04 UFP/100 mL. Finalmente, las muestras de agua clorinada arrojaron tres resultados positivos con una media geométrica de 1,07 UFP/ mL (Tabla 2 y 3 ).

Tabla 3. Resumen de los recuentos de indicadores microbiológicos en la Planta de Tratamiento № 1 - La Atarjea.

\begin{tabular}{llcc}
\hline Indicadores & Muestras de agua & Rango de recuentos & Media geométrica \\
\hline Coliformes & Bocatoma* & $13000-500000$ & 56340,08 \\
Totales & Decantada** $^{*}$ & $0-13$ & 2,04 \\
& Filtrada** & $0-8$ & 2,13 \\
& Clorada** $^{*}$ & - & - \\
Coliformes & Bocatoma* $^{*}$ & $2000-27000$ & 14074,96 \\
Termotolerantes & Decantada** & $0-9$ & 1,67 \\
& Filtrada** & $0-4$ & 1,81 \\
Bacterias & Clorada** & - & - \\
Heterótrofas & Bocatoma & $7900-4500000$ & 75478,12 \\
(UFC/mL) & Decantada & $450-3200000$ & 48394,43 \\
& Filtrada & $300-720000$ & 17378,00 \\
Colifagos & Clorada & $0-11$ & 2,23 \\
(UFP/100 mL) & Bocatoma & $1010-3800$ & 2267,25 \\
& Decantada & $0-12$ & 2,11 \\
& Filtrada & $0-13$ & 2,04 \\
Clorada & $0-2$ & 1,07 \\
\hline
\end{tabular}

* (NMP/100 mL), **(UFC/100 mL) 


\section{Determinación de la Correlación entre los Colifagos y los Coliformes Totales y Termotolerantes}

Para determinar la validez de la relación entre los microorganismos evaluados, se utilizo el índice de correlación de Pearson (Wayne, 1993). Para una aproximacion a la normalización se transformaron los valores a logaritmo en base 10, las variables correlacioandas fueron los Colifagos, los Coliformes Totales y Coliformes Termotolerantes.

En las muestras de agua no tratadas («Bocatoma») se obtuvieron coeficientes de correlación (r) igual a 0,3048 entre los colifagos y los CT, y de 0,7129 entre los colifagos y CTT. Asimismo, para las muestras de agua decantada la correlación r entre colifagos y los CT y CTT fueron de 0,3793 y 0,5326 respectivamente. Finalmente los coeficientes de correlación entre colifagos con respecto a CT y CTT para las muestras de agua filtrada fueron de $0,3629 \mathrm{y}$ 0,4612 respectivamente (Tabla 4).

Luego de realizar las pruebas estadísticas de hipótesis correspondientes se determinó que todas las correlaciones entre los colifagos y los CT y CTT son significativas $(\mathrm{p}<0,05)$, excepto entre los colifagos y los CT en muestras de agua de «Bocatoma» que no fue significativa $(\mathrm{p}>0,05)$.

Para predecir el número de CT y CTT a partir de la cuantificación de los colifagos se realizó el análisis estadístico de regresión en-

Tabla 4. Coeficientes de correlación de Pearson entre los recuentos de Colifagos, Coliformes Totales y ColiformesTermotolerantes en las fases del tratamiento del agua en La Atarjea. Para un total de $n=40$ muestras de agua analizadas. $\mathrm{NS}=$ no significativo, $\left({ }^{*}\right)=$ significativo al $95 \%$ de confianza.

\begin{tabular}{|c|c|c|c|}
\hline & & $\begin{array}{l}\text { Coliformes } \\
\text { Totales }\end{array}$ & $\begin{array}{c}\text { Coliformes } \\
\text { Termotolerantes }\end{array}$ \\
\hline \multirow{3}{*}{$\begin{array}{l}0 \\
0 \\
\stackrel{\infty}{\pi} \\
\stackrel{0}{0} \\
0 \\
0\end{array}$} & "Bocatoma" & $0,3048 \mathrm{NS}$ & $0,7129\left(^{*}\right)$ \\
\hline & Agua decantada & $\left.0,3793 \quad{ }^{*}\right)$ & 0,5326 \\
\hline & Agua filtrada & $0,3629 \quad(*)$ & $0,4612(*)$ \\
\hline
\end{tabular}

tre estos indicadores. En la Tabla 5 se presentan las ecuaciones obtenidas para las muestras de agua de «Bocatoma», agua decantada y agua filtrada.

\section{Determinación del porcentaje de remoción de los microorganismos indicadores}

En la Tabla 6 se presentan los porcentajes de muestras positivas y de remoción de los diferentes microorganismos indicadores en los puntos de tratamiento evaluados. El porcentaje de muestras positivas para las $\mathrm{BH}$ fue del $100 \%$ en todos los puntos de tratamiento excepto para el agua clorinada que fue del $75 \%$. Asimismo, los porcentajes de remoción de $\mathrm{BH}$ en las muestras de agua decantada, filtrada y clorinada alcanzaron el 35,88; 76,98 y 99,99\% respectivamente.

En relación a los CT, las muestras positivas alcanzadas en los diferentes puntos de muestreo fueron de $100 ; 67,5$ y $65 \%$ para el agua de «Bocatoma», decantada y filtrada respectivamente; siendo los porcentajes de remoción en los mismos puntos de 99,996\% para las muestras de agua decantada y filtrada. No se encontró muestras positivas en el agua clorinada, siendo el porcentaje de remoción de $>99,999 \%$.

Con respecto a los CTT las muestras positivas alcanzadas en los puntos de muestreo fueron del $100 ; 57,5$ y $62,5 \%$ en las muestras de agua de «Bocatoma», decantada y filtrada respectivamente, no encontrándose muestras positivas en agua clorinada. En consecuencia los porcentajes de remoción de CTT fueron del 99,998 y 99,987\% en las muestras de agua decantada y filtrada respectivamente, y $>99,999 \%$ en las muestras de agua clorinada.

Finalmente, los porcentajes de muestras positivas para colifagos fue del $100 \%$ para muestras de agua de «Bocatoma», $50 \%$ para muestras de agua decantada, $45 \%$ para muestras de agua filtrada y $7,5 \%$ para muestras de agua clorinada. Los porcentajes de remoción alcanzados en cada punto de muestreo fueron del $99,91 \%$ en las muestras de agua decantada y 
Tabla 5. Ecuaciones de estimación de Coliformes Totales y Coliformes Termotolerantes en función al recuento de Colifagos. $Y=$ Logaritmo de Coliformes Totales o Termotolerantes, $\mathrm{X}=$ Logaritmo de Colifagos.

"Bocatoma":

Coliformes Termotolerantes vs Colifagos

$$
\mathrm{Y}=1,2577 \mathrm{X}+0,0912
$$

Agua decantada
Coliformes Totales vs Colifagos
\[ \mathrm{Y}=0,3057 \mathrm{X}+0,2115 \]
Coliformes Termotolerantes vs Colifagos
\[ \mathrm{Y}=0,3203 \mathrm{X}+0,1063 \]
Coliformes $\quad$ Totales vs Colifagos
Y $=0,2714 \mathrm{X}+0,2444$
Coliformes Termotolerantes vs Colifagos
$\mathrm{Y}=0,1742 \mathrm{X}+0,2698$

NOTA: No se consideran las ecuaciones para el agua clorada debido a los resultados negativos

filtrada, y del 99,95\% en las muestras de agua clorinada.

\section{Pruebas complementarias}

Las muestras de agua de «Bocatoma», agua decantada, agua filtrada y agua clorinada tuvieron un $\mathrm{pH}$ con medias geométricas de 8,45; 7,54; 7,51 y 7,26 respectivamente, y una turbiedad expresada en Unidades Nefelométricas de Turbiedad (NTU) con medias geométricas de 14,25; 4,$05 ; 1,36$ y 0,82 respectivamente. La media geométrica del cloro residual en muestras de agua clorinada fue de $0,83 \mathrm{mg} / \mathrm{mL}$.

\section{Discusión}

El método de la Capa Simple sugerido por la American Public Health Association (1989) es la técnica más adecuada para la cuantificación de colifagos en muestras de agua altamente contaminadas como son las muestras de agua de «Bocatoma». Esta técnica ha sido utilizada con buenos resultados en trabajos previos (Zevallos, 1997; El-Abagy et al., 1989) y tiene la ventaja de ser simple y rápida (los resultados se obtienen dentro de las 3-4 horas de incubación).
El uso de colifagos como indicadores de contaminación fecal y de la remoción de microorganismos durante el proceso de tratamiento del agua era difícil debido a que los métodos existentes para su detección estaban limitados a muestras de pequeño volumen o requerían procedimientos y equipos complejos adaptados de los usados para la detección de virus entéricos. El método de la Membrana Filtrante (Alonso et al., 1994; Sobsey et al., 1990) demostró ser eficiente para la cuantificación de bajas concentraciones de colifagos en muestras de aguas tratadas, por su sencillez, rapidez en obtener los resultados (6-8 horas de incubación) y la ventaja de poder analizar grandes volúmenes de muestra (100-1000 mL).

Al determinar la correlación de los colifagos con los CT y CTT para establecer su validez como indicador de contaminación fecal, se encontró correlación estadísticamente significativas entre los colifagos y los CTT en muestras de agua de «Bocatoma» con un $\mathrm{r}$ de 0,71 (p>0,05). Zevallos (1997) en la misma planta de tratamiento encontró un $\mathrm{r}$ igual a $0,54 \mathrm{y}$ Borrego et al. (1987) analizando muestras de río encontraron un $r$ igual a 0,78 . Moriñigo et al. (1992) encontraron un rigual a 0,62, mientras que Dutka et al. (1987) usando los métodos de Filtro de Membrana y tubos múltiples encontraron $r$ iguales a 0,38 y 0,41 respectivamente, en tanto que, Wentsel et al. (1982) encontraron un $r$ igual a 0,69 .

No se encontró correlación significativa entre los colifagos y los CT en muestras de agua de «Bocatoma» (Tabla 4) en coincidencia con Zevallos (1997), Moriñigo et al. (1992) y Borrego et al. (1987), quienes proponen por esta razón no usar a los CT como indicadores de contaminación fecal en ambientes acuáticos de alta contaminación.

Del análisis de las muestras de agua decantada se encontraron $r$ iguales a 0,38 $(\mathrm{p}<0,05)$ y $0,53(\mathrm{p}<0,05)$ entre los colifagos $y$ los CT y CTT respectivamente. Para las muestras de agua filtrada se encontraron $r$ iguales 
Tabla 6. Remoción de los indicadores microbiológicos durante el tratamiento del agua en la Planta de Tratamiento $N^{\circ} 1$ «La Atarjea»

\begin{tabular}{lrcccr}
\hline Indicadores & $\begin{array}{r}\text { Muestras de } \\
\text { agua } \\
\text { analizadas }\end{array}$ & $\begin{array}{c}\text { Número de } \\
\text { muestras } \\
\text { positivas }\end{array}$ & $\begin{array}{c}\text { Número } \\
\text { muestras } \\
\text { positivas }\end{array}$ & $\begin{array}{c}\text { Porcentaje } \\
\text { muestras }\end{array}$ & $\begin{array}{r}\text { Porcentaje } \\
\text { remoción }\end{array}$ \\
\hline \multirow{3}{*}{ Coliformes } & Bocatoma & 40 & 40 & 100 & - \\
Totales & Decantada & 40 & 27 & 67,5 & 99,9964 \\
& Filtrada & 40 & 26 & 65 & 99,9962 \\
Coliformes & Clorada & 40 & 0 & 0 & $>99,9999$ \\
Termotolerantes & Bocatoma & 40 & 40 & 100 & - \\
& Decantada & 40 & 23 & 57,5 & 99,9881 \\
Biltrada & 40 & 25 & 62,5 & 99,9872 \\
Hacterias & Clorada & 40 & 0 & 0 & $>99,9999$ \\
Heterótrof & Bocatoma & 40 & 40 & 100 & - \\
& Decantada & 40 & 40 & 100 & 35,8830 \\
& Filtrada & 40 & 40 & 100 & 76,9761 \\
Colifagos & Clorada & 40 & 30 & 75 & 99,9970 \\
& Bocatoma & 40 & 40 & 100 & - \\
& Decantada & 40 & 20 & 50 & 99,9069 \\
& Filtrada & 40 & 18 & 45 & 99,9100 \\
& Clorada & 40 & 3 & 7,5 & 99,9528 \\
\hline
\end{tabular}

a $0,36(\mathrm{p}<0,05)$ y $0,46(\mathrm{p}<0.005)$ respectivamente. Al respecto, Zevallos (1997) encontró para muestras de agua filtrada $\mathrm{r}$ iguales a 0,71 y 0,79 entre los colifagos y los CT y CTT respectivamente.

Al analizar las muestras de agua clorinada se observó que de las cuarenta muestras evaluadas tres fueron positivas para colifagos y ninguna para CT y CTT (Tabla 2), demostrándose que pueden aislarse colifagos en ausencia de coliformes. Similares resultados fueron obtenidos por Zevallos (1997); Ratto et al. (1989), El-Abagy et al. (1988) y Wentsel et al. (1982), quienes a su vez demuestran que los colifagos resisten mejor el tratamiento y desinfección del agua que los coliformes, siendo por lo tanto buenos indicadores de contaminación fecal en aguas tratadas. Más aún, existen varios estudios que demuestran la existencia de una correlación estadísticamente significativa entre los colifagos y los enterovirus. Payment y Franco (1993) encontraron un coeficiente de correlación igual a 0,54 en agua decantada y 0,40 en agua filtrada; mientras que Stetler (1984) encontró un r igual a 0,54 en agua filtrada, demostrando que los colifagos son buenos indicadores de contaminación fecal en aguas tratadas.

Al hacer el análisis de regresión para estimar el número de CT y CTT a partir del recuento de colifagos (Tabla 5) las ecuaciones obtenidas difieren de las determinadas por Zevallos (1997): $y=0,5264 X+2,7038$ entre colifagos y CTT en muestras de Bocatoma, y $=0,434 \mathrm{X}+0,4398$ entre colifagos y CTT en muestras de agua filtrada, $\mathrm{y}=0,3745 \mathrm{X}+0,7087$ entre colifagos y CT en muestras de agua filtrada. Borrego et al. (1987) obtuvieron la siguiente ecuación entre los colifagos y los CTT : y $=0,7250 X+0,8141$; en cambio, Dutka et al. (1987) y APHA (1989) obtuvieron las siguientes ecuaciones: In colifagos $=0,8294+$ $0,2255 \ln$ coliformes fecales, y $\log \mathrm{Y}=$ $0,85(\log X)+0,895$ respectivamente para estimar el número de coliformes fecales a partir del recuento de colifagos en muestras de agua de río. La poca similitud entre estas ecuaciones puede deberse a factores ambien- 
tales de contaminación y supervivencia de los microorganismos indicadores en los cuerpos de agua, ya que cada uno de ellos posee características propias, como lo propone IAWPRC (1991).

En las muestras evaluadas de «Bocatoma», la diferencia entre las ecuaciones determinadas puede explicarse debido a las variaciones estacionales que producen fluctuaciones en las concentraciones de colifagos y coliformes. Se observa que las medias geométricas de los colifagos, CT y CTT en el periodo evaluado en este estudio (junio-septiembre) fueron de 2267,25 UFP/100 mL, 5,65x10 UFC/100 mL y $1,41 \times 10^{4} \mathrm{UFC} / 100 \mathrm{~mL}$ respectivamente (Tabla 3), mientras que en el periodo evaluado por Zevallos (1997) (marzo - junio), las medias geométricas fueron de 1819,65 UFP/100 $\mathrm{mL}, 1,75 \times 10^{5} \mathrm{UFC} / 100 \mathrm{~mL}$ y $2,67 \times 10^{4} \mathrm{UFC} /$ $100 \mathrm{~mL}$ respectivamente. Stetler (1984) reportó la existencia de cambios estacionales en la población de colifagos durante el periodo de Otoño - Invierno donde la recuperación de colifagos fue de 3,5 veces al periodo de Primavera - Verano. Esta variación estacional también se presentó para los enterovirus en el mismo periodo de Otoño - Invierno y fue de 4,0 veces al periodo de Primavera - Verano. Variaciones similares fueron encontradas por Keswick et al. (1984) al observar que las concentraciones de colifagos, enterovirus, coliformes fecales y coliformes totales aumentaban durante la estación lluviosa del año y disminuían durante la estación seca.

Con respecto al porcentaje de remoción de los microorganismos indicadores durante el proceso de tratamiento se observó en forma general una disminución progresiva durante cada nivel de tratamiento evaluado, tanto en la concentración de los microorganismos indicadores como en el porcentaje de muestras positivas. A su vez se determinó que la remoción final fue mayor para los CT y CTT, seguido de las $\mathrm{BH}$ y de los colifagos (Tabla 6). Resultados similares fueron obtenidos por Payment (1991) en Canadá al estudiar una planta de tratamiento que incluía predesinfección con cloro u ozono, floculación, decantación, filtración, ozonización y postclorinación. La remoción final en las muestras de agua decantada de CT y CTT fue $>99,99 \%$, de las BH del 99,99\% y de los colifagos del 99,95\%; en cambio, en las muestras de agua filtrada y clorinada el porcentaje de remoción de colifagos fue del 99,99\%. Igualmente, Jofre et al. (1995) encontraron resultados semejantes para los colifagos al estudiar dos plantas de tratamiento en España, con porcentajes de remoción finales $>99,99 \%$ y del $99,99 \%$ observando además que la remoción no descendía progresivamente sino que se mantenía en niveles semejantes hasta el final del tratamiento, indicando que la mayor remoción se produce después de la preclorinación - floculación siendo de menor importancia en los subsiguientes pasos. Payment y Franco (1993) en otro estudio establecen que el proceso de tratamiento de una planta que incluye un proceso de floculación, decantación y filtración se aplica para reducir los niveles de materia orgánica disuelta y en suspensión para asegurar una apropiada desinfección final del agua, pudiendo el porcentaje de remoción de los microorganismos indicadores sufrir pequeñas variaciones en los pasos anteriormente mencionados.

Los resultados obtenidos en este estudio permiten apreciar que las $\mathrm{BH}$ resisten mejor el proceso de tratamiento que los coliformes, tanto en porcentaje de remoción como en porcentaje de muestras positivas (Tabla 6). Ello puede deberse a la mayor concentración que presentan al inicio del proceso y a su heterogeneidad como grupo, existiendo bacterias que resisten mejor la cloración, por lo cual son utilizadas como indicadoras para el monitoreo general del proceso de tratamiento y desinfección, así como de contaminación secundaria en los sistemas de distribución (Grabow, 1986), pero no como indicadores específicos de contaminación fecal.

En cambio, los colifagos al presentar correlación con los coliformes durante el tratamiento y resistencia a la desinfección, detec- 
tándose en aguas finales con limites aceptables de $\mathrm{pH}(7,23)$, turbiedad $(0,82 \mathrm{NTU})$, cloro residual $(0,83 \mathrm{~g} / \mathrm{L})$ y ausencia de coliformes, demuestran que son buenos indicadores de contaminación fecal y de remoción de la carga microbiana tal como se establece en este estudio y otros autores (Zevallos, 1997; Ratto et al. 1989; Stetler, 1984).

\section{Literatura citada}

Alonso, M.; J. Sánchez, M. Moriñigo, J. Borrego. 1994. A Direct membrane filter method for enumerating somatic coliphages in drinking water. Microbiología SEM 10, 285-296.

APHA 1989. Standard methods for the Examination of Water and Wastewater, 16ava. Ed. American Public Health Association, Washington, D.C.

Barzola, C.; C. Lazcano, T. Agurto. 1995a. Demanda de cloro frente a dosis - respuesta bacteriana en aguas del río Rímac (Bocatoma-Atarjea). LimaPerú. En Resúmenes del IX Congreso Peruano de Microbiología y Parasitología. Asociación Peruana de Microbiología. Lima-Perú.

Barzola, C.; C. Lazcano, T. Agurto. 1995b. Demanda de cloro frente a dosis - respuesta bacteriana en agua filtrada de la Planta No 1 - Atarjea. LimaPerú. En Resúmenes del IX Congreso Peruano de Microbiología y Parasitología. Asociación Peruana de Microbiología. Lima-Perú.

Borrego, J.; M. Moriñigo, A. De Vicente, R. Córnax, P. Romero. 1987. Colifagos as an Indicator of fecal pollution in water. It relationship with indicator and pathogenic microorganism. Water Res. 21, 1473-1480.

Borrego, J.; R. Córnax, M. Moriñigo, E. Martínez, P. Romero. 1990. Coliphages as an indicator of fecal pollution en water. Their survival and productive infectivity in natural aquatic environments. Wat. Res. 24, 111-116.

Córnax, R.; M. Moriñigo, C. Balebona, D. Castro, J. Borrego. 1991. Significance of several bacteriophage groups as indicators of sewage pollution in marine waters. Wat. Res. 25, 673-678.

Dutka, B.; A. El-Shaarawi, M. Martins, P. Sánchez. 1987. North and South American studies on the potential of coliphages a water quality indicator. Wat. Res. 21, 1127-1134.

El-Abagy, M.; B. Dutka, \& M. Kamel. 1989. Incidence of coliphage in potable water supplies. Appl. Environ. Microbiol. 54, 1632-1633.

Grawow, W. 1986. Indicators systems for assessment of virological safety of treated drinking water. Wat. Sci. Tech. 18, 159-165.
Grabow, W.; P. Coubrough, E. Nupen, B. Bateman. 1984. Evaluation of coliphages as indicator of the virological quality of sewage-polluted waters. Water SA. 10, 7-14.

Jofre, J.; E. Olle, F. Lucena, F. Ribas. 1995 Bacteriophage removal in water treatment plants. Wat. Sci.Tech. 31, 69-73

Keswick, B.; Ch. Gerba, H. Dupont, J. Rose. 1984. Detection of enteric viruses in treated drinking water. Appl. Environ. Microbial. 47, 12901324

IAWPRC; Study Group On Health Related Water Microbiology 1991. Bacteriophages as model viruses in water quality control. Wat. Res. 25, 529-545.

Moriñigo, M.; D. Wheeler, Ch. Berry, C. Jones, M. Muñoz, R. Córnax, J. Borrego. 1992. Evaluation of different bacteriophages groups as fecal indicators in contaminated natural waters in Southern England. Wat. Res. 26, 267-271.

Payment, P. 1991. Elimination of coliphages, Clostridium perfringens and human enteric viruses during drinking water treatment: results of large volume samplings. Wat. Sci. Tech. 24, 213-215.

Payment, P. \& E. Franco. 1993. Clostridium perfringens and somatic coliphages as indicators of the efficiency of drinking water treatment for viruses and protozoan cysts. Appl. Environ. Microbiology. 59, 2418-2424.

Ratto, A.; B. Dutka, C. Vega, C. López, A. El-Shaarawi. (1989). Potable water safety assessed by coliphage and bacterial test. Wat. Res. 23, 253-255.

Sobsey, M.; K. Schwab \& T. Handzel. 1990. A simple membrane filter method to concentrate and enumerated male-especific RNA coliphages. J. Am. Wat. Wks. Ass. 82, 52-59.

Stetler, R. 1984. Coliphages as indicators of enteroviruses. Appl. Environ. Microbiol. 48, 668-670.

Wayne, D. 1993. Bioestadística. Base para el análisis de las ciencias de la salud. Tercera edición. Limusa. Noriega editores. 676 pág.

Wentzel, R.; P. O’neil \& J. Kitchems. 1982. Evaluation of coliphage detection as a rapid indicator of water quality. Appl. Environ. Microbiol. 43, 430-434.

Zevallos, P. 1997. Evaluación de colifagos como indicadores alternativos de contaminación fecal en la planta de Tratamiento de Agua de La Atarjea. Lima- Perú. Tesis de Licenciatura en Biología. Universidad Nacional Federico Villarreal. 